\title{
Aplicação do interferômetro de Sagnac para detecção de perturbações mecânicas e localização
}

\author{
Gaglioti, S. F. ${ }^{1}$; Pontes, M.J. ${ }^{1}$ \\ 1 Programa de Pós-Graduação em Engenharia Elétrica, Universidade Federal do Espírito Santo, Vitória, ES, Brasil
}

\begin{abstract}
Resumo
Este trabalho descreve o experimento baseado em um modelo conhecido de sensor de intrusão e localização baseado em um interferômetro de Sagnac. O modelo foi alimentado com as condições experimentais disponíveis para prever os resultados antes da montagem do experimento. Diferentes condições foram testadas, como bobinas de fibra óptica com comprimentos maiores e atenuadores variáveis para simular o posicionamento das perturbações mecânicas.
\end{abstract}

Palavras chave: Sagnac, interferômetro, localização.

\section{Introdução}

De forma geral, fibras ópticas podem ser utilizadas como sensores para medição de grandezas físicas como pressão, rotação, deslocamento mecânico, temperatura, intensidade de corrente elétrica, deformação mecânica, campo magnético e elétrico entre outros. Ao mesmo tempo, transmitem o sinal detectado até o sistema de aquisição e processamento [1].

Aplicações recentes envolvem o uso de sensores interferométricos para detecção de perturbação ou intrusão. Sistemas de segurança também utilizam sensores baseados em fibras ópticas para proteção de perímetros ou monitoração de áreas que exigem vigilância permanente [2].

O sensor interferométrico de Sagnac (figura 1), é classificado como um interferômetro de duas ondas, pois nele propagam duas ondas que percorrem dois caminhos diferentes (em sentidos opostos): uma é definida como sinal e outra, como referência. Em um giroscópio, por exemplo, uma bobina girando a uma dada velocidade angular, as ondas de sinal e referência são detectadas em instantes de tempo diferentes, resultando em uma diferença de fase proporcional ao comprimento total da fibra e também a seu diâmetro e velocidade angular [1].

\section{Modelo}

O conceito é baseado em dois sistemas independentes e fisicamente sobrepostos, montados na configuração de sensores interferométricos de Sagnac. O modelo conhecido [2] explora as proporções de atenuação no anel que compõe o interferômetro de Sagnac e utiliza um anel adicional como referência para localizar a perturbação mecânica. Para satisfazer o sistema, duas montagens definidas como Montagem 1 (M1) e Montagem 2 (M2) produzem as potências $P_{1}^{\prime}(t)$ e $P_{2}^{\prime}(t)$ respectivamente. A perturbação mecânica é aplicada simultaneamente aos dois interferômetros o que resulta na detecção de dois sinais com intensidades distintas. Estas intensidades detectadas são aplicadas a um sistema de duas equações e duas incógnitas, o que permite determinar a distância onde a perturbação ocorreu [2], conforme (1).

$$
d 1= \pm \frac{L \cos ^{-1}\left(1-P_{1}^{\prime}\right)}{\cos ^{-1}\left(1-P_{2}^{\prime}\right)-\cos ^{-1}\left(1-P_{1}^{\prime}\right)}
$$

Onde $P_{1}^{\prime}(t)$ é a potência normalizada de $\mathrm{M} 1$ e $P_{2}^{\prime}(t)$ a potência normalizada de M2. L é o comprimento da bobina central.

\section{Experimento}

O primeiro experimento foi reproduzido com bobinas de comprimento $L=25 \mathrm{~km}$ e $2 \mathrm{~L}=50 \mathrm{~km}$. Esta montagem não 
apresentou resultados satisfatórios, pois devido a sua sensibilidade, detectou um elevado nível de ruído. Outro problema é a detecção indireta das perturbações através das bobinas ao invés do trecho onde foi aplicada a perturbação (fibra sensora), invalidando as medições. Uma opção para evitar estes problemas é utilizar bobinas menores. Outra opção é a aplicação de atenuadores fixos e variáveis combinados no lugar das bobinas. Esta foi a opção escolhida e as montagens representadas na figura 1

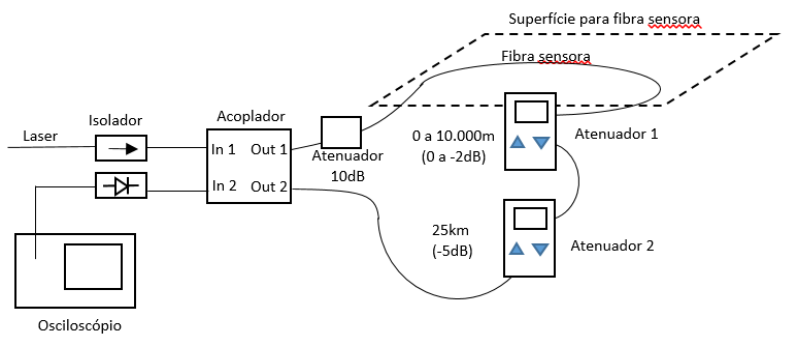

Figura 1. Montagem M2. A montagem M1 é idêntica, porém, não utiliza o atenuador de $10 \mathrm{~dB}$

O laser utilizado é tipo DFB com potência de $-2,85 \mathrm{dBm}$. O acoplador é 50/50. A fibra sensora é SMF desencapada, com $3 \mathrm{~m}$ de comprimento. As perturbações foram aplicadas através de um sistema com mola e fim de curso que proporcionaram ótima repetibilidade. Cada medição foi repetida 7 vezes.

Considerando uma perda de $0,2 \mathrm{~dB} / \mathrm{km}$, os atenuadores foram ajustados a cada $0,2 \mathrm{~dB}$ para que as medições refletissem uma perda equivalente a $1 \mathrm{~km}$ de fibra óptica. Na montagem M1, o Atenuador 2 representa a bobina de $25 \mathrm{~km}$, ajustado com uma atenuação fixa equivalente $(5 \mathrm{~dB})$. O Atenuador 1 simula a localização do ponto $P$ através de um ajuste escalonado, sendo acrescentados $0,2 \mathrm{~dB}$ a cada $1 \mathrm{~km}$, chegando ao total de $2 \mathrm{~dB}(10 \mathrm{~km})$.

A montagem M2 é idêntica à montagem M1, mas com um atenuador de $10 \mathrm{~dB}$ posicionado no local onde estaria uma bobina de complementar de comprimento $2 \mathrm{~L}(50 \mathrm{~km})$.

A intensidade da perturbação e a disposição das fibras foram mantidos constantes durante os experimentos nas duas montagens e durante as medições, variando apenas os valores do Atenuador 1 .

As medições de intensidade das perturbações mecânicas foram realizadas de forma independente em cada montagem e aplicadas na equação que determina d1. Foi necessário aplicar um fator de ajuste de 0,28 para sobrepor os resultados calculados e medidos, uma vez que as equações previstas nos estudos teóricos [2] não consideram perdas por inserção, ruídos em geral, polarização e outros.
A figura 2 compara os resultados medidos e calculados com base no modelo proposto.

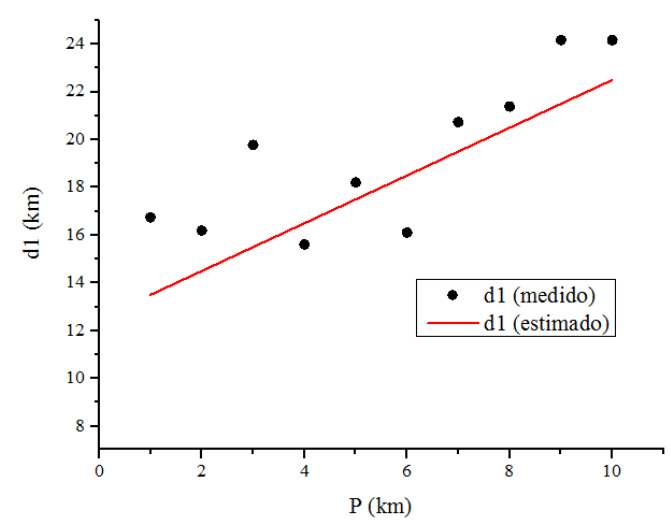

Figura 2. Sobreposição dos resultados práticos e previstos.

\section{Conclusão}

O experimento comprova os resultados previstos no modelo. O fator de ajuste deve ser revisto a cada experimento, uma vez que o interferômetro e os demais componentes podem sofrer variações em seu funcionamento em função da temperatura, ruído ambiente ou até mesmo da disposição das fibras. As perdas por inserção também são fatores importantes e variam a cada montagem, influenciando nos resultados.

Para uma solução comercial, deve ser desenvolvido um sistema de processamento de sinais para filtrar sinais produzidos naturalmente como vento, animais, veículos, folhas caindo, chuva e outros [2].

\section{Agradecimentos}

Os autores agradecem a colaboração dos alunos Hozianna C. B. Ximenes, Rodolfo L. Silva e do Prof. Moisés Ribeiro na realização e discussões deste trabalho.

\section{Referências}

[1] A. B. Lobo Ribeiro, "Sensores interferométricos em Fibra óptica”, Gaz. de Física, FASC. 1, pp 16-21, 1998.

[2] A. D. McAulaya e J. Wangb "A Sagnac Interferometer Sensor System for Intrusion Detection and Localization", Proc SPIE Vol. 5435, Enabling Photonic Technologies for Aerospace Applications VI", doi:10.1117/12.542834,

[3] J. M. L. Higuera, Handbook of Optical Fibre Sensing , WILEY, 2001. 